\title{
Poland syndrome in an 18-year-old man
}

\author{
Tsung-Han Ho MD, Chun-Chieh Wang MD
}

Cite as: CMAJ 2019 July 15;191:E793. doi: 10.1503/cmaj.190135

A n 18-year-old man presented to our outpatient pulmonary clinic with a flattened left breast region causing chest wall asymmetry. The condition did not affect his activities of daily living, except for the inability to lift heavy weights with his left hand. He did not have any history of trauma or surgery in the corresponding areas. Examination showed an absence of the sternocostal portion of the left pectoralis major muscle (Figure $1 \mathrm{~A}$ ), of which the clavicular part was preserved and more hypertrophic than that on the right. The patient had a smaller and superiorly displaced ipsilateral nipple. A chest radiograph (Figure $1 \mathrm{~B}$ ) showed hyperlucency of the left hemithorax along with an asymmetric left horizontal axillary fold. No vascular anomalies were identified in the subsequent thoracocervical computed tomographic angiography.

The clinical and radiographic features were diagnostic of Poland syndrome, an uncommon, sporadic congenital musculoskeletal disorder arising from interruption of the unilateral subclavian artery supplying the thoracic wall and upper extremity. This likely occurred during embryonic development, leading to stunted growth of the tissues subtended by the artery. Clinical manifestations of Poland syndrome are highly variable. Ipsilateral involvement of the chest muscles is the most striking hallmark, and usually presents as complete or partial agenesis of the pectoralis major, contributing to the abnormal contour of the anterior axillary border and compensatory hypertrophy of the residual synergistic muscles. ${ }^{1}$ The insufficient arterial blood supply may also result in mammary hypoplasia; malformation of the shoulder girdle, ribs or digits; axillary alopecia; and malposition of the thoracic organs. ${ }^{1}$
Poland syndrome is mostly benign, although there are reports of associated malignancies, including leukemia, non-Hodgkin lymphoma, and breast and lung carcinomas. ${ }^{2,3}$ Treatment is primarily reconstructive surgery, depending on the severity of the malformation, cosmetic appearance and functional performance. ${ }^{1-3}$ Our patient favoured surveillance by regular follow-up in the outpatient department.

\section{References}

1. Ribeiro RC, Saltz R, Mangles MG, et al. Clinical and radiographic Poland syndrome classification: a proposal. Aesthet Surg J 2009;29:494-504.

2. Al Faleh K, Al Saadi M, Khalid-Bantuas S. Poland's syndrome with absent limb anomalies. J Clin Neonatol 2014;3:44-6.

3. Huang Y, Pang H, Jin S, et al. Clinical characteristics of Poland's syndrome associated with breast cancer: two case reports and a literature review. J Cancer Res Ther 2018;14:1665-9.

\section{Competing interests: None declared.}

This article has been peer reviewed.

The authors have obtained patient consent.
Affiliations: Department of Neurology (Ho), Tri-Service General Hospital, National Defense Medical Center, Taipei, Taiwan; Division of Chest Medicine (Wang), Department of Internal Medicine, Taichung Veterans General Hospital Puli Branch, Nantou, Taiwan

Correspondence to: Chun-Chieh Wang, proteinmad@yahoo.com.tw 